\title{
Australians' use of surrogacy
}

\section{Sam G Everingham \\ BSC, MA, MPH \\ Research Director \\ Martyn A Stafford-Bell \\ MBBS, FRCOG, FRANZCOG \\ Medical Director ${ }^{2}$ \\ Karin Hammarberg \\ $\mathrm{RN}, \mathrm{BSc}, \mathrm{PhD}$ \\ Senior Research Fellow ${ }^{3}$ \\ 1 Surrogacy Australia, \\ Sydney, NSW. \\ 2 Canberra Fertility Centre, \\ Canberra, ACT \\ 3 Jean Hailes Research Unit, School of Public Health \\ and Preventive Medicine, \\ Monash University, \\ Melbourne, VIC.}

sam@

surrogacyaustralia.org

MJA 2014; 201: 1-4 doi: 10.5694/mjal3.11311

Online first 15/08/14
T

raditional surrogacy, using the surrogate's own eggs, has its origins in antiquity. ${ }^{1}$ Today, gestational surrogacy - where a woman agrees to carry a child for another person or couple, known as the intended parent(s), with the intention that the child will be raised by them is more common. The oocytes and/or sperm used to create the embryo(s) in the surrogacy cycle can be either from the intended parents or from a donor or donors. ${ }^{2}$

Surrogacy is described as uncompensated or altruistic when the surrogate mother receives reimbursement only for out-of-pocket expenses (eg, medical costs) associated with pregnancy and birth. In compensated surrogacy, the surrogate is financially rewarded for the work of carrying a pregnancy for a third party.

Surrogacy may be used when the uterus is absent or not able to carry a pregnancy; when the female partner for medical reasons cannot gestate a pregnancy; in cases of recurrent failed implantation and recurrent idiopathic miscarriage; or when a single male or same-sex male couple uses assisted reproductive technologies to have children. ${ }^{3,4}$

Compensated surrogacy is illegal in all Australian jurisdictions, and in some it is also a criminal offence to undertake surrogacy overseas. Uncompensated surrogacy is regulated in most states. 5

State surrogacy-related laws and Regulations are shown in Appendix 1 and Appendix 2 (online at mja.com.au). Parentage orders to allow the intended parents to replace the surrogate on the birth certificate are available through the supreme courts of states where altruistic arrangements take place.

A retrospective audit of overseas surrogacy agencies carried out by Surrogacy Australia in 2011 showed a $277 \%$ increase in the number of infants born to Australians via surrogacy, with numbers rising from 97 in 2009 to 269 in 2011 (unpublished

\section{Abstract}

Objectives: To investigate the characteristics of parents and intended parents and their current and planned behaviour in relation to surrogacy arrangements.

Design, setting and participants: Members of two Australian parenting support forums who were considering surrogacy or were currently or previously in a surrogacy arrangement were invited to complete an online survey during July 2013.

Main outcome measures: Sociodemographic characteristics; proportions engaging in domestic uncompensated and overseas compensated arrangements; countries used; costs incurred; and impact on behaviour of state laws criminalising compensated surrogacy.

Results: Of 1135 potential participants, 312 (27\%) commenced the survey. Of these, 24 did not fulfil inclusion criteria and 29 did not complete the survey. Eighty-nine respondents were considering surrogacy and 170 had commenced or completed surrogacy. Many respondents (53\%) considered both overseas and domestic surrogacy. Among those who only considered one option, overseas surrogacy was considered significantly more often than domestic surrogacy ( $92 \%$ v $8 \%$; $P<0.05$ ). Only 22 respondents ( $8 \%$ ) commenced with a surrogate in Australia. The most common countries used for compensated surrogacy were India and the United States, and average total estimated costs were $\$ 69212$ for India and $\$ 172347$ for the US. Barriers discouraging domestic surrogacy included concern that the surrogate might keep the child (75\%), belief that it was too long and complicated a process (68\%) and having no one of the right age or life stage to ask (61\%). Few intended parents ( $9 \%)$ were deterred by state laws criminalising compensated surrogacy.

Conclusions: Most Australian intended parents via surrogacy consider or use overseas compensated arrangements. Laws banning compensated surrogacy do not appear to deter those seeking surrogacy arrangements.

data presented at the first Surrogacy Australia National Conference, 2011 May 30-31; Melbourne. Everingham S. Money time and conviction: how Australians are accessing surrogacy; and data obtained under freedom of information request FA 12/03/009356).

Monetary remuneration of surrogates is legal in some states of the United States and in some other countries, including India, Thailand and Ukraine. In 2008, over 2500 gestational surrogacy cycles were reported by US in vitro fertilisation (IVF) clinics that are members of the Society for Assisted Reproductive Technology (ART). Current numbers are expected to be far higher. ${ }^{7}$

Little is known about the experiences of Australian intended parents who consider or undertake surrogacy. We aimed to investigate the characteristics of Australian intended parents, their previous use of ART, current and planned behaviour in relation to surrogacy arrangements, the financial cost of such arrangements, and the impact on behaviour of state laws banning compensated surrogacy.

\section{Methods}

In July 2013, Surrogacy Australia (www.surrogacyaustralia.org) in partnership with Monash University conducted an anonymous online survey of Australian parents and intended parents via surrogacy. The 90-item survey comprised mostly fixed-choice questions about sociodemographic characteristics; previous ART use; planned, current and past surrogacy use; impact on behaviour of state legislation banning compensated surrogacy; and barriers to undertaking surrogacy in Australia. It was pilot tested with intended and existing parents through surrogacy. Ethics approval was granted by the Monash University Human Research Ethics Committee. 


\begin{tabular}{|c|c|}
\hline Characteristic & Number (\%) \\
\hline \multicolumn{2}{|l|}{$\operatorname{Sex}(n=259)$} \\
\hline Male & $145(56 \%)$ \\
\hline Female & 114 (44\%) \\
\hline Relationship status & $(n=259)$ \\
\hline Single & $26(10 \%)$ \\
\hline De facto & $121(47 \%)$ \\
\hline Married & $112(43 \%)$ \\
\hline Household income* & $(n=250)$ \\
\hline$<\$ 77999$ & $27(11 \%)$ \\
\hline$\$ 78000-\$ 103999$ & 35 (14\%) \\
\hline \$104 999-\$129999 & 38 (15\%) \\
\hline$\$ 130000-\$ 155999$ & 30 (12\%) \\
\hline \$156000-\$181999 & $27(11 \%)$ \\
\hline$\$ 182000-\$ 207999$ & $20(8 \%)$ \\
\hline$>\$ 208000$ & 73 (29\%) \\
\hline Sexuality & $(n=259)$ \\
\hline Heterosexual & $132(51 \%)$ \\
\hline Gay & 127 (49\%) \\
\hline
\end{tabular}

\section{Inclusion criteria}

To be eligible, respondents needed to be Australian residents and to be considering surrogacy, be in a current uncompensated or compensated surrogacy agreement, or have been in such an agreement in the past.

\section{Recruitment}

Invitations with a link to the survey were emailed to members of Surrogacy Australia and Gay Dads Australia (www.gaydadsaustralia.com.au) online forums. The invitation specified the above inclusion criteria. Of 1135 potential participants, 312 commenced the survey - a $27 \%$ response rate. Of these, 24 were excluded because they did not meet the inclusion criteria.

\begin{tabular}{|c|c|c|}
\hline \multirow[b]{2}{*}{ Response option } & \multicolumn{2}{|c|}{ Type of surrogacy arrangement, no. (\%) } \\
\hline & Uncompensated & Compensated \\
\hline Considered but ruled out & $45(17 \%)$ & - \\
\hline Currently considering & $22(8 \%)$ & $89(34 \%)$ \\
\hline $\begin{array}{l}\text { Considered but unable to locate a suitable } \\
\text { surrogate }\end{array}$ & $79(31 \%)$ & - \\
\hline Commenced but not successful & $7(3 \%)$ & $8(3 \%)$ \\
\hline Currently undertaking & $14(5 \%)$ & $57(22 \%)$ \\
\hline Successful surrogacy arrangement & $1(<1 \%)$ & $103(40 \%)$ \\
\hline
\end{tabular}

\section{Statistical analysis}

Data were analysed by $Q$ analysis software using descriptive statistics (www.q-researchsoftware.com). Univariate comparisons were made using the Student $t$ test and $\chi^{2}$ statistics. Twenty-nine respondents did not answer all questions, and where the number of available responses is lower than the number of participants, this is indicated.

\section{Results}

\section{Sample characteristics}

Of the 288 eligible respondents who commenced the survey, 259 completed it. Their sociodemographic characteristics are shown in Box 1. Respondents' mean age was 40 years (range 19-64 years) and they came from every Australian state and territory.

Eighty-nine respondents were considering surrogacy and 170 had commenced or completed surrogacy. The numbers of respondents currently considering and using uncompensated and compensated surrogacy and who had used surrogacy in the past are shown in Box 2. Nine of 14 who had commenced an uncompensated arrangement were still considering a compensated arrangement. Further, 22 of those who were currently in a compensated arrangement already had a child through an earlier compensated arrangement.

Only one respondent reported having one or more children through domestic uncompensated surrogacy and 103 (40\%) had had one or more children through compensated surrogacy undertaken overseas. Of this latter group, 53 (51\%) reported having had two or more children.

\section{ART experiences}

Of 130 heterosexual respondents, 84 (65\%) had engaged with an Australian ART clinic in the past. The mean number of years spent trying to conceive naturally before seeking help was 4.5 (SD, 3.9). Those who had undergone infertility treatment in Australia (64 [76\%]) reported having had a mean number of 1.4 inseminations (SD, 2.3) and 7.8 (SD, 5.4) embryo transfers spread over 5.7 years before turning to surrogacy. The mean time spent trying to conceive (naturally and through ART) before considering surrogacy was thus over 10 years. The mean reported outof-pocket cost of ART was \$33219. For 12 respondents, ART had resulted in the birth of a child, but further ART to have a subsequent child had resulted in repeated failed implantation.

\section{Uncompensated versus compensated surrogacy}

Of the 259 respondents, almost half (114 [44\%]) did not consider uncompensated surrogacy. The main reasons respondents did not consider surrogacy in Australia were a concern that the surrogate might decide to keep the child (86 [75\%]), a belief that it was too long and complicated a process (78 [68\%]) and having no one of the right age or life stage to ask (69 [61\%]). Concern that carrying a child for no reward was an unfair exchange was also often cited (53 [46\%]).

Of the 146 who considered or used uncompensated surrogacy, 87 (60\%) were heterosexual. Most of those who considered uncompensated surrogacy (105 [72\%]) had not commenced the process in Australia.

Of those who considered or used uncompensated surrogacy, 101 (69\%) attempted to find a surrogate. Of the $41(41 \%)$ who were able to find a surrogate, 26 did not proceed. The main stated reasons for not proceeding were the perceived length of the process (8); a concern that accepting a relative or friend's offer to be a surrogate risked damaging the relationship (5); the surrogate changing her mind (4); and a belief it was illegal (3). Of the 22 who commenced with a surrogate in Australia, 16 did so through an ART clinic, while six entered private arrangements using their surrogate's own eggs.

More than half of the respondents (137 [53\%]) considered both overseas 
3 Rate of use of countries for compensated surrogacy arrangements, by year contract was signed $(n=143)$

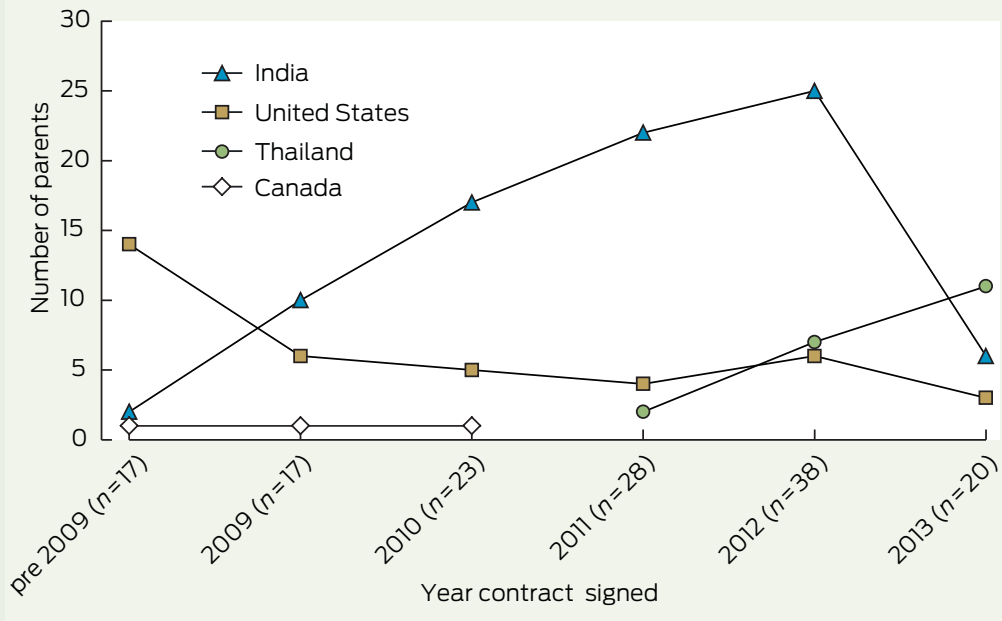

4 Total cost to respondents for compensated surrogacy arrangements, by year contracted $(n=108)$

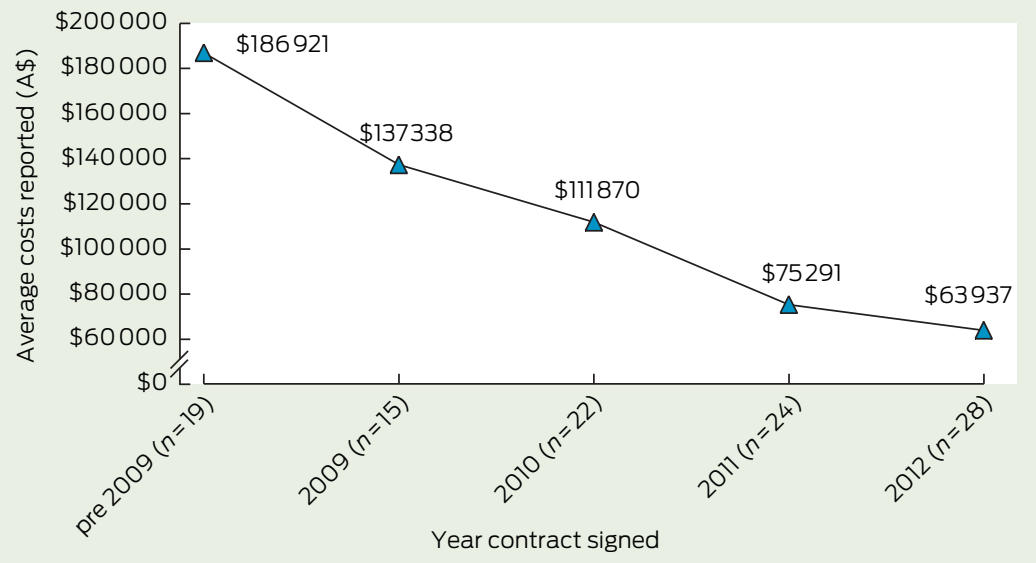

and domestic surrogacy. Of 123 who only considered one option, a significantly higher proportion considered overseas compensated surrogacy (92\% [113] v 8\% [10]; $P<0.05 ; z=2.8$ ).

The country where most compensated surrogacy arrangements took place varied over time. Among the 143 respondents with a current or previous compensated arrangement, the US was the most commonly used country before 2009 (Box 3). India fast became the destination of choice until 2012, when new visa rules restricted access to surrogacy to married heterosexual couples. A rise in popularity of Thailand since 2011 is apparent.

\section{Costs and future intentions}

Respondents who were currently in uncompensated surrogacy arrangements (14) had spent an average of $\$ 27690$ to date. Five of those reporting unsuccessful arrangements reported having spent, on average, $\$ 14460$. The single respondent who had a successful uncompensated surrogacy reported spending $\$ 41800$,

Among those who had completed a successful compensated surrogacy arrangement, mean total estimated costs were $149 \%$ higher for the US (\$172347) compared with India (\$69212) (Appendix 3; online at mja.com.au). A downward trend in compensated surrogacy costs over recent years was evident (Box 4).

Overall, 60\% (155) were likely, very likely or definitely going to engage in future compensated surrogacy. Among those who already had one or more children via this route, $40 \%$ (41/103) were likely, very likely or definitely going to do this again. of which $57 \%$ was the cost of IVF.

\section{Impact on behaviour of} criminalisation laws

Respondents were asked to imagine they were considering an overseas compensated surrogacy arrangement and were resident in a state where laws made this a criminal offence. Such laws were a deterrent for only $9 \%$ of respondents (23). Of the 114 who actually lived in Australian states with criminalisation laws, 63 (55\%) would enter an overseas compensated surrogacy contract, based on a low probability of prosecution, and another 26 (23\%) would move to a state where overseas compensated surrogacy is not criminalised (Box 5).

\section{Discussion}

Surrogacy presents a range of social, medical, psychological, financial and legal challenges for those who use these arrangements. This study is the first to elucidate the characteristics, attitudes and behaviours of Australians contemplating or using surrogacy as a means to have children. As the number of surrogacy arrangements undertaken by Australians is increasing, it is important for policymakers, lawmakers and health professionals in the field of ART to understand the needs and experiences of those who use them.

Our results showed that surrogacy arrangements are accessed by both heterosexual and gay couples as well as single men and women; there are many perceived barriers to using domestic uncompensated surrogacy arrangements and few proceed with these; most consider or use compensated surrogacy overseas, mainly in the US, India and Thailand; state laws prohibiting compensated surrogacy do not appear to deter most people from using it; and considerable costs are incurred by those who do.

Given that just over a quarter of the available sample responded, and $10 \%$ of these failed to complete all questions, our results may not be representative of the entire target population. Indeed, parents whose experiences of surrogacy were particularly negative may have been more reluctant to relive that experience through participating in the survey. However, the relatively large sample and its sociodemographic diversity, as well as the variety of experiences and arrangements described by participants, provide some assurance that a broad 


\section{Responses to the question "How would you respond if considering overseas surrogacy and living in a state where this is a} criminal offence?"

\section{Participant would:}

Living in a state with criminalising law,*\% (no.)

Engage in compensated overseas surrogacy given
low probability of prosecution

low probability of prosecution

Move to state where compensated overseas surrogacy not illegal

Pursue other options (eg, fostering)

Rule out adding to family

Don't know

$(n=114)$
$55 \%(63)$
$23 \%(26)$
$12 \%(14)$
$4 \%(4)$
$6 \%(7)$

Living in a state with no criminalising law, ${ }^{\dagger} \%$ (no.)
Proportion of total respondents, \% (no.)

\section{$(n=259)$}

$42 \%(109)$

$32 \%(46)$

$50 \%(72)$

$38 \%(98)$

* Queensland, Australian Capital Territory or New South Wales. † Western Australia, Victoria, South Australia, Northern Territory or Tasmania.

range of parents and intended parents responded.

The low number of successful uncompensated arrangements observed in this study is supported by Australian perinatal data, which in 2011 recorded just 21 births via regulated surrogacy. ${ }^{8}$ This is in contrast to data from a survey of just 12 popular agencies showing over 270 babies were born overseas to Australians during 2011 (unpublished data presented at the first Surrogacy Australia National Conference, 2011 May 30-31; Melbourne. Everingham S. Money time and conviction - how Australians are accessing surrogacy).

Average costs reported for surrogacy within Australia and overseas are substantial. In addition, many had spent large amounts on unsuccessful ART before considering surrogacy. The \$19017 average reported for completed successful (one) and unsuccessful (five) uncompensated arrangements in Australia is likely to be unreliable given the small base and the fact that the average spend on uncompensated surrogacy still in progress was over $\$ 27000$, with significant amounts still to be incurred. However, costs for overseas surrogacy were significantly greater. It is therefore not surprising that respondents reported far higher household incomes than most Australian couple families with no children. ${ }^{9}$ This suggests that intended parents accessing surrogacy self-select based on ability to pay and that the high costs associated with surrogacy, both overseas and within Australia, discriminate against less financially secure Australians.

Our results confirm anecdotal reports that in the wake of India introducing mandatory surrogacy visas from late 2012 that exclude gay, single and de facto intended parents, there has been a marked decline in India as a destination for surrogacy. Thailand appears to be taking India's place in compensated arrangements.

Among those engaging in surrogacy in Australia, we found that a high proportion engage in private arrangements outside ART clinic environments (presumably using the surrogate's own eggs). The high reported costs and mandated controls associated with regulated surrogacy in Australia may contribute to this practice.

By accessing unregulated surrogacy either at home or overseas, Australians forgo potential benefits, such as expert preparatory counselling, transfer of intended parents' name(s) to the birth certificate, and legal recognition of parentage. Lack of preparatory counselling, in particular, risks all parties being ill prepared and may increase the risks of conflict and separation distress for surrogate mothers. However, unregulated surrogacy (in overseas settings) also has benefits, as it avoids the need for intended parents to find a surrogate themselves as well as the lengthy delays associated with ethics committee approval.

The high proportion of intended parents using overseas instead of domestic surrogacy arrangements shows that Australian public policy in this area is failing. Legally accessible uncompensated surrogacy processes clearly do not meet the needs of many. Further, state-based legislation criminalising overseas compensated surrogacy is not stopping the practice. It appears that the drive to have a child for people who need surrogacy is greater than the barriers erected by Australian legislators.

In the interests of facilitating more equitable access to surrogacy arrangements within Australia, there is a need to review surrogacy-related laws, regulations, processes and requirements.
Allowing surrogates to receive some compensation for the work of carrying a pregnancy might make it easier to recruit surrogates in Australia and avoid the need for people to undertake unregulated surrogacy overseas.

Competing interests: Sam Everingham is on the management committee of Surrogacy Australia, a notfor-profit consumer association supporting research and advocacy in the field of surrogacy. He runs a professional market research consultancy and has received fees for conducting research and reporting time. Martyn Stafford-Bell is on the Steering Group of Reproduction and Collaborative Trials in Australia and New Zealand. Karin Hammarberg is a part-time staff member at the Victorian Assisted Reproductive Treatment Authority.

Received 13 Oct 2013, accepted 17 Mar 2014.

1 Bromham DR. Surrogacy: ethical, legal, and social aspects. J Assist Reprod Genet 1995; 12: 509-516.

2 English ME, Mechanick-Braverman A, Corson SL. Semantics and science: the distinction between gestational carrier and traditional surrogacy options. Womens Health Issues 1991; 1: 155-157.

3 Stafford-Bell MA, Copeland CM. Surrogacy in Australia: implantation rates have implications for embryo quality and uterine receptivity. Reprod Fertil Dev 2001; 13: 99-104.

4 Ethics Committee of the American Society for Reproductive Medicine. Using family members as gamete donors or surrogates. Fertil Steril 2012; 98 797-803.

5 Millbank J. The new surrogacy parental laws in Australia: cautious regulation or ' 25 brick walls'? Melbourne UL Rev 2011; 35: 165-207.

6 Australian Government Department of Immigration and Citizenship. Statistics on the number of citizenship by descent applications granted to infants by posts in India and the USA from 1 January 2008 to 31 December 2011. http://www.immi.gov.au/About/foi/Pages/ disclosure-log-2012.aspx (accessed Aug 2014).

7 Gugucheva M. Surrogacy in America. Cambridge, Mass: Council for Responsible Genetics, 2010. www. councilforresponsiblegenetics.org/pagedocuments/ kaevej0alm.pdf (accessed Mar 2014).

8 Macaldowie A, Wang YA, Chambers GM, Sullivan EA. Assisted reproductive technology in Australia and New Zealand 2011. Sydney: National Perinatal Epidemiology and Statistics Unit, University of New South Wales, 2013.http://www.npesu.unsw.edu.au/sites/default/ files/npesu/surveillances/Assisted reproductve technology in Australia and New Zealand 2011.pdf (accessed Mar 2014).

9 Australian Bureau of Statistics. Census of population and housing: expanded community profile, 2011 second release. Canberra: ABS, 2012. (ABS Cat. No. 2005.0.) http://www.abs.gov.au/AUSSTATS/abs@.nsf/ Lookup/2005.0Main+Features12011\%20Second\%20 Release?OpenDocument (accessed Mar 2014). 